\title{
A Gestão da Clínica em questão
}

\author{
Clinical Governance in question
}

\author{
Romeu Gomes ${ }^{1} \bowtie$, Valéria Vernaschi Lima ${ }^{2}$
}

${ }^{1}$ Doutor em Saúde Pública. Professor do Hospital Sírio-Libanês. Editor-chefe da revista Ciência \& Saúde Coletiva. São Paulo, SP.

2 Doutora em Saúde Pública. Professora Associada da Universidade Federal de São Carlos. São Carlos, SP.

\section{RESUMO}

A discussão da Gestão da Clínica demanda uma abordagem que leve em conta questões relacionadas ao poder e ao papel dos diferentes atores na produção e gestão da saúde. Nesse sentido, busca-se uma transformação das práticas de atenção, gestão e da própria educação para que possam produzir uma atenção integral voltada para necessidades de saúde das pessoas e populações. Para isso, faz-se necessário considerar todos os envolvidos nesse processo e apoiar a leitura da realidade por meio da criticidade e da capacidade de dialogar diferentes perspectivas, incluindo a das pessoas sob cuidado, dos profissionais de saúde e da gestão de sistemas de saúde.

DESCRITORES: Gestão da Clínica; assistência à saúde; sistemas de saúde; gestão em saúde.

\section{ABSTRACT}

The discussion of Clinical Governance requires an approach that takes into account issues related to the power and role of different actors in production and management of the health. In this sense, it is sought a transformation of the practices of attention, management and of the own education so that they can produce an integral attention directed to the health needs of the people and populations. To do this, it is necessary to consider all those involved in this process and support the reading of reality through the criticality and the ability to dialogue different perspectives, including that of caregivers, health professionals and health systems management.

KEY WORDS: Clinical Governance; delivery of health care; health systems; health management.

$\mathrm{G}$ overnança Clínica, Gestión Clínica e Gestão da Clínica: expressões que se equivalem? Ainda que possamos estabelecer interseções entre esses termos, eles não integram uma total sinonímia. Surgiram a partir de demandas específicas em cenários nacionais distintos e têm escopos diferenciados.

Num contexto onde lidamos com (i) a presença de mudanças no perfil demográfico e epidemiológico das populações, onde há a persistência de doenças agudas e o avanço de doenças crônicas; (ii) a possibilidade de indução da demanda pela oferta, em função do pagamento por procedimento; (iii) o papel dos profissionais de saúde, em função do seu domínio sobre os saberes para o cuidado à saúde; (iv) a identificação de melhores práticas na investigação e tratamento de doenças, decorrentes de inovações tecnológicas e da saúde baseada em evidências; e (v) diferentes perspectivas daqueles que fazem a gestão dos serviços e dos que atuam diretamente no cuidado à saúde; a organização e o modelo de respostas dos sistemas de saúde vêm sendo fortemente tensionados.

Nesse cenário, indicadores da atuação dos sistemas de saúde que apontam os custos crescentes da assistência, o consumo excessivo de procedimentos e de medicamentos, a fragmentação do trabalho em saúde com qualidade inconstante, a presença de uma variabilidade sem lastro em evidências científicas e a baixa confiança da população na atuação de determinados serviços podem ser considerados elementos disparadores das mudanças na relação entre a gestão e a clínica.

A Governança Clínica surgiu nos anos 90 do século passado no Reino Unido, no âmbito do National Health Service [1], voltando-se para o comprometimento de organizações de saúde com a melhoria contínua de seus serviços e a manutenção de elevados padrões de cuidados, por meio de um ambiente propício à excelência clínica [2]. Esse movimento influenciou outros sistemas de saúde a definirem e implantarem 
políticas e diretrizes para assegurar a melhoria da qualidade da clínica. Desde a sua criação, a Governança Clínica foi incorporada na literatura com diferentes sentidos a ela atribuída, podendo ser sintetizados em sete temas que sintetizam a análise das fontes: gestão, promoção da qualidade, monitoramento ou auditoria clínica, educação, responsabilidade, segurança no cuidado e dimensão sistêmica [3].

Gestión Clínica é utilizada, na Espanha, objetivando principalmente a atenção integral, coordenada e centrada no paciente, buscando incorporar elementos da gestão no cotidiano do trabalho clínico [4]. Nela, são contemplados aspectos tais como: qualidade e efetividade, objetivos comuns de todos os agentes envolvidos, descentralização progressiva, autonomia e corresponsabilização na obtenção de resultados [5].

A expressão Gestão da Clínica foi empregada no Brasil por Mendes em 2001, trazendo elementos tanto da Atenção Gerenciada, amplamente disseminada nos Estados Unidos nos anos 1980, como da Governança Clínica. Segundo o autor, a Gestão da Clínica compreende um conjunto de tecnologias de microgestão aplicáveis ao Sistema Único de Saúde brasileiro que, baseadas nas diretrizes clínicas, utiliza a "gestão da condição de saúde, de gestão de caso, de auditoria clínica e de listas de espera" para prover uma atenção à saúde de qualidade [6].
Ao explorarem os desafios da aproximação entre gestão e clínica, outros autores do campo da saúde coletiva e da administração apontam a necessidade de ampliarmos a interpretação desse fenômeno pela problematização da categoria poder e do papel dos diferentes sujeitos na produção e gestão da saúde [7-9].

Recente trabalho dedicado à identificação dos princípios que orientariam uma Gestão da Clínica transformadora destaca o papel da educação como dispositivo para a transformação das práticas de atenção, gestão e da própria educação. Para transformar, no sentido da produção de uma atenção integral à saúde, com qualidade e segurança, e orientada às necessidades de saúde das pessoas e populações, os autores defendem que todos os envolvidos nesse processo sejam considerados legítimos e sejam apoiados na ampliação da leitura da realidade por meio da criticidade e da capacidade de dialogar diferentes perspectivas, incluindo a das pessoas sob cuidado, dos profissionais de saúde e da gestão de sistemas de saúde [10].

Por fim, a título de exemplificar a utilização da Gestão da Clínica em um cenário hospitalar, a Scientia Medica apresenta, neste fascículo, estudo que - ao promover a associação entre o contexto do trabalho assistencial de retaguarda e as melhorias nos processos de cuidado - evidencia o alcance de maior oferta de leitos aos usuários [11].

\section{REFERÊNCIAS}

1. National Health Service. The NHS in England [internet]. [cited April 23, 2016]. Available from: http://www.nhs.uk/ NHSEngland/thenhs/about/Pages/overview.aspx

2. Scally G, Donaldson LJ. Clinical governance and the drive for quality improvement in the new NHS in England. BMJ 1998; 317(7150):61-65. https://doi.org/10.1136/bmj.317.7150.61

3. Gomes R, Lima VV, Oliveira JM, Schiesari LMC, Soeiro E, Damázio LF, Petta HL, Oliveira MS, Silva FS, Sampaio SF, Padilha RQ, Machado JLM, Caleman G. A Polissemia da Gestão da Clínica: uma revisão de literatura. Ciên \& Saúde Colet. 2005;20(8):241-9

4. Consorci Hospitalari de Catalunya CHC - Consultoria i Gestión. Gestión Clinica: Conceptos, herramientas y operativizacion. Apresentação no Simpósio Internacional de Cirurgia Segura e Gestão da Clínica, 11 de novembro de 2008. Hospital Sírio-Libanês, São Paulo, SP, Brasil.

5. Temes JLM, Parra B. Gestión Clínica. Madrid: Mc Graw Hill Interamericana, 2000.

6. Mendes EV. As redes de atenção à saúde. Brasília: Organização Pan-Americana da Saúde, 2011

7. Cecilo LCO. Autonomia versus controle dos trabalhadores: a gestão do poder no hospital. Ciên \& Saúde Colet. 1999;4(2):315-29. https://doi.org/10.1590/S1413-81231999000200007

8. Merhy EE. Em busca da qualidade dos serviços de saúde: os serviços de porta aberta para a saúde e o modelo tecnoassistencial em defesa da vida. In: Cecilio LCO (org.). Inventando a mudança na saúde. São Paulo: Hucitec, 1994, p. 117-60.

9. Campos GWS, Amaral M. A clínica ampliada e compartilhada, a gestão democrática e redes de atenção como referenciais teórico-operacionais para a reforma do hospital. Ciên \& Saúde Colet. 2007;12(4):849-59. https://doi.org/10.1590/S141381232007000400007

10. Padilha RQ, Gomes R, Lima VV, Soeiro E, Oliveira JM, Schiesari LMC, Silva SF, Oliveira MS. Princípios para a gestão da clínica: conectando gestão, atenção à saúde e educação na saúde. Ciên \& Saúde Colet [periódico na internet] 2017 jun. [Citado em 8 de junho 2017]; [cerca de 15 p.] Available from: http://www.cienciaesaudecoletiva.com.br

11. Anschau F, Webster J, Roessler N, Fernandes EO, Klafke V, da Silva CP, Mersseshmidt G, Ferreira S, Fagundes SMS, Fossari JAJ. Avaliação de intervenções de Gestão da Clínica na qualificação do cuidado e na oferta de leitos em um hospital público de grande porte. Sci Med. 2017;27(2):ID26575. https://doi.org/10.15448/1980-6108.2017.2.26575 C 